

\title{
RESPONSE OF ANOPHELES GAMBIAE DETOXIFICATION ENZYMES TO LEVELS OF PHYSICO-CHEMICAL ENVIRONMENTAL FACTORS FROM NORTHWEST NIGERIA
}

\author{
Abdullahi, A. Imam, ${ }^{1}$ and Yusuf, Y. Deeni ${ }^{2}$ \\ ${ }^{1}$ Department of Biochemistry. Faculty of Basic Medical Sciences, College of Health Sciences, Bayero University \\ Kano. P. M. B. 3011 Kano-Nigeria \\ ${ }^{2}$ Scottish Informatics, Mathematics, Biology and Statistics (SIMBIOS) Centre and Abertay Centre for the \\ Environment (ACE), School of Science, Engineering and Technology, University of Abertay Dundee, Dundee, DD1 \\ $1 \mathrm{HG}$, Scotland, United Kingdom \\ * Correspondence author: aaimam.bch@buk.edu.ng
}

\begin{abstract}
The objective of this study was to investigate the response of Anopheles gambiae detoxification enzymes to levels of various physico-chemical environmental factors present in their breeding sites. Mosquito breeding sites were grouped into three different breeding sites (designated as study zones A, B \& C) on the bases of human related activities (intensive agriculture, petrochemical and domestic) taking place within and/or around the breeding sites, followed by sampling of Anopheles gambiae larvae from all the breeding sites across the designated study zones. Some of the sampled larvae were reared to pupae and adult life stages. Levels of 7 physical (pH, temperature, conductivity, transparency, total dissolved solids, dissolved oxygen and biological oxygen demand) and 6 chemical (sulphates, phosphates, nitrites, nitrates, carbon content and oil and grease) environmental factors were determined from these mosquito breeding sites. Activities of the 3 major detoxification enzymes (Cytochrome P450 oxygenase, GST and a \& $\beta$-esterases) were evaluated in the sampled larvae as well as the pupae and adult samples that ultimately emerged from the larvae. Following statistical analysis, results showed that P450 activities were higher in the petrochemical sites (zone C) and the activities were highly associated with pH, temperature as well as carbon content and oil and grease. The activities of GST and $a \& \beta$ esterases were higher in the intensive agriculture sites (Zone A) and were highly correlated with all the chemicals environmental factors. A deduced statistical model established all the chemical in combination with some of the physical environmental factors as producing an inductive effect on these three detoxification enzymes. These observations could have a significant impact on the insecticide-based approach to vector control. An. gambiae samples may have developed intrinsic enzymatic machinery to produce an adaptive tolerance to various insecticides used for their control since most of these insecticides and the environmental chemical factors share similar routes of metabolism.
\end{abstract}

Keywords: Cytochrome, Anopheles, Inescts, Northwestern Nigeria

\section{INTRODUCTION}

Insects, like most eukaryotes, have evolved a complex capacity to transform compounds they encounter in their environments. The development of this ability is very important to their survival particularly in chemically unfriendly environments. All insects possess detoxification mechanisms, but the type, nature and capacity differs in different insect species, developmental stages, and the type of the environmental exposure (Yu, 2005). Mosquitoes are of particular interest because of their role as vector of many parasitic diseases including malaria, yellow fever, dengue fever etc. For mosquitoes like other insect species, the challenge of responding to varieties of xenobiotic assault is compounded by the varieties of breeding ecologies and food sources upon which they rely for their life cycle. The mosquito aquatic breeding sites contain varieties of microorganisms, vegetating materials, toxic phenolic compounds of plant degradation, various chemicals deliberately and directly applied to control their abundance, chemical runoff from industries, farmlands, and other forms of human activities (Strode et al., 2006). The ubiquity of mosquito breeding habitats mean that mosquitoes are found in virtually all environments from arctic to the deserts (Budiansky, 2002). An. gambiae in particular is a highly anthropophilic malaria vector distributed widely in Sub-Saharan Africa. This region constitutes $90 \%$ of the global malaria burden (WHO, 2013). Exposure of $A n$. gambiae to this array of environmental xenobiotics could undoubtedly selects them for adaptive responses. Some of these responses could constitute challenges to insecticidebased approaches to malaria management and control initiatives (Strode et al., 2006).

An elaborate three phase detoxification system is used by all animal species including $A n$. gambiae to defend themselves against the toxic effects of these environmental xenobiotic substances. The three phase system metabolises the toxic substance into a less harmful one and excrete them out of the cell (Xu et al., 2005). 
Among these detoxification phases, the phase I detoxification mechanism is the most elaborate; employing activities of enzymes belonging to the P450 family. In phase II, the by-product of phase I reaction are further detoxified by means of enzymes belonging to the GST and a \& $\beta$-esterases families. When organisms are exposed to environmental toxicants, a transcriptional response is activated which leads to upregulation of the genes involved in the detoxification machinery (Misra et al., 2011). This is called induction (Poupardin et al., 2008) . Induction of detoxification enzymes in response to xenobiotic exposure has received greater attention in higher animals, because of its important implication in drug metabolism and discovery. Studies on induction of detoxification enzymes in insect vectors have tended to focus more on adaptation; how a particular strain of insect has adapted to a particular environment which could then selects it for insecticides resistance (Perry et al., 2011). However, evidences have emerged that insects like other higher animals have the ability to regulate the transcription of detoxification genes in response to environmental xenobiotics.

The first documented evidence of enzyme induction in insects was given by Agnosin and Dinamarca (1963), in which they reported an increased activity of NAD Kinase in Triatoma infestans after exposure to DDT. Evidences are beginning to emerge of the induction of the three major detoxification enzyme systems in insects; P450 cytochromes, GST and Carboxyl esterases (Suwanchaichinda and Brattsen, 2002). A comprehensive review on the incidences of induction of these enzymes by various xenobiotics in many species of insects have been well documented (David et al., 2013). Aedes mosquitoes and Drosophila have featured most prominently in many recent studies (Suwanchaichinda and Brattsen, 2001, 2002; Boyer et al., 2006; Poupardin et al., 2008; and Riaz et al., 2009) involving induction of one or more of the detoxification enzymes in response to various environmental xenobiotics (Misra et al., 2011). However, An. gambiae, a major malaria vector, has not featured prominently in studies involving the relationships between xenobiotic exposure and induction of detoxification enzymes. Although, the inductive ability of detoxification genes in An. gambiae in response to insecticides like permethrin was demonstrated (Vontas et al., 2005), the role of prior exposure to varieties of environmental chemicals has not been largely investigated. These kinds of studies are especially important given the ability of Anopheles mosquitoes to thrive in varieties of contaminated environments. Therefore, the aim of this present study is to establish the potentiality of different physico-chemical environmental factors as driving a selection pressure for the emergence and development of insecticides resistance in An. gambiae. This is because of the similarity in structures, functions and activity relationships between these environmental factors and several synthetic insecticides used in mosquito control. The hypothesis here is that prior exposure of products containing these chemical species present in $A n$. gambiae breeding ecologies, could exerts a selection pressure that could drive an intrinsic and acquired capacity in An. gambiae towards tolerance to several types of insecticides used for its control.

\section{MATERIAL AND METHODS Study zones and Sites}

The study was conducted across three different breeding sites designated as study zones A, B \& C. These zones were differentiated by the type of human related activities taking place around the mosquito breeding sites i.e. A; intensive agricultural areas; $B$, residential areas; and $C$, areas where petrochemical products are sold, processed, used and/or discharged. The breeding sites located in intensive agricultural zones and petrochemical areas consist of small puddles of stagnant water bodies. The water was found to be muddy, dirty, oily and obviously contaminated. The breeding sites in the domestic areas were larger with higher water volume and relatively clean. A total of three sites in study zone $A$, four in zone $B$ and three in zone $C$ were visited and sampled across the Nigerian states of Kano and Jigawa. Kano is situated in the northwest and has a four-season climate with a typical temperature range of $11-44^{\circ} \mathrm{C}$ and yearly rainfall of $1000 \mathrm{~mm}$ (NIMET, 2012). Jigawa is also situated in the northwest, and is characterized by a Sahel savannah climate with a typical temperature range of $10-42^{\circ} \mathrm{C}$ and a yearly rainfall of less than $800 \mathrm{~mm}$ (John, 2007; SEEDS, 2009 and NIMET, 2012).

\section{Larval Sampling}

Sampling of mosquito larvae from each of the breeding sites was conducted at least once a week throughout the field study period (June-September, 2011). Stagnant water bodies within or around farmlands, residential areas and sites of petrochemical commercial activities were sampled using a standard mosquito dipper as described by Service (Service, 1993).

\section{Water chemistry analysis}

Conductivity, $\mathrm{pH}$, temperature, and total dissolved solids were measured using COMBO $\mathrm{PH} / \mathrm{EC} / \mathrm{TDS} /$ Temperature metre (HANNA Instruments, United States). Transparency (Turbidity) was determined using a secchi disc (Maiti, 2004). Dissolved oxygen (DO) and biological oxygen demand (BOD) were determined using a DO meter (Hach Lange, Colorado-United States) as described by Maiti (2004). Nitrate $\left(\mathrm{NO}_{3}{ }^{-}\right)$, Nitrite $\left(\mathrm{NO}_{2}{ }^{-}\right)$, Phosphate $\left(\mathrm{PO}_{3}{ }^{2-}\right.$ ) and Sulphate $\left(\mathrm{SO}_{4}{ }^{2-}\right)$ concentrations were determined by the sulphanilamide-N-(1-naphthyl)ethylenediamine dihydrochloride (NED dihydrochloride) colorimetric, phenol disulphonic acid, stannous-chloride and turbidimetric methods, respectively. Carbon content (total organic carbon) was determined using the Lange TOC cuvette-test (Hatch Lange LCK 385, Salford, United Kingdom). Levels of oil and grease were determined by the liquid-liquid extraction method (Maiti, 2004). Analytical grade chemicals and reagents used were from SigmaAldrich (United Kingdom) and BDH chemicals (VWR International Ltd. United Kingdom) unless otherwise indicated. 


\section{Detoxification Enzymes Assays}

Assay of the three major detoxification enzymes, cytochrome P450 (P450), glutathione transferase (GST) and a \& $\beta$-Esterases, was carried out using procedures outlined by WHO (1998).

\section{Preparation of mosquito homogenate}

Twenty mosquito larvae were homogenised in ice-cold phosphate buffer $(0.1 \mathrm{M}$; $\mathrm{pH} 7.2)$ in $1.5 \mathrm{ml}$ microfuge tubes with Pellet Pestle Motor (Kontes Anachem, Mettler Toledo, Luton, Bedfordshire, UK). The homogenization was carried out on ice. After the homogenization, the homogenates were centrifuged for I minutes in a refrigerated centrifuge (Eppendorf Centrifuge 5417R, Motor Park Way, New York, United States) and the supernatants used for the assays. All the mosquito larvae used were of $4^{\text {th }}$ instar, roughly of the same size.

\section{P450 Activity Assay (WHO, 1998)}

Twenty (20) $\mu \mathrm{L}$ mosquito homogenate were mixed with $80 \mu \mathrm{L}$ of potassium phosphate buffer in a microtitre plate well and $200 \mu \mathrm{L}$ of the working solution $(5 \mathrm{ml}$ methanol solution of $0.002 \mathrm{mg} / \mathrm{ml}$ of $3,3^{1}, 5,5^{1}$-tetramethyl benzidine in $15 \mathrm{ml}$ of $0.25 \mathrm{M}$ sodium acetate buffer; pH 5.0) was added. Finally, 25 $\mu \mathrm{L}$ of $3 \%$ hydrogen peroxide was added to the well. The mixture was incubated at room temperature for 2 $\mathrm{h}$ and the absorbance was read at $650 \mathrm{~nm}$ using a microplate reader (Modulus Microplate Reader; Turner Biosystems Sunnyvale, California, United States). Control and calibration standards (varying concentrations of standard cytochrome C) were treated similarly and all assays were performed in triplicates. P450 activity was estimated by comparing absorbance values with a standard calibration curve of absorbance for known concentrations of cytochrome C. The values are reported as equivalent units of cytochrome $\mathrm{P} 450 / \mathrm{mg}$ protein, correcting for the known haem content of cytochrome C and P450.

\section{GST Assay (WHO 1998).}

Ten (10) $\mu \mathrm{L}$ mosquito homogenate were mixed with $200 \mu \mathrm{L}$ of GSH/CDNB working solution (125 $\mu \mathrm{L}$ of 63 $\mathrm{mM}$ CDNB in $2.5 \mathrm{ml}$ of $10 \mathrm{mM}$ GSH solution) in a microtitre plate well. The reaction was read immediately at $340 \mathrm{~nm}$ as a kinetic assay for $5 \mathrm{~min}$. Blanks were prepared with $10 \mu \mathrm{L}$ of the phosphate buffer mixed with $200 \mu \mathrm{L}$ of the GSH/CDNB working solution and all the assays were performed in triplicates. The GST activity was reported as $\mu \mathrm{mol}$ CDNB conjugated/min/mg protein, using published extinction coefficient corrected for the path length.

\section{Esterase Assay (WHO, 1998)}

Twenty (20) $\mu \mathrm{L}$ mosquito homogenate were mixed with $200 \mu \mathrm{L}$ of 1 -Naphthyl working solution $(1 \mathrm{ml}$ of $30 \mathrm{mM}$ 1-Naphthyl acetate mixed with $99 \mathrm{ml}$ of potassium phosphate buffer; $\mathrm{pH}$ 7.2) and 2-Naphthyl acetate working solution (1 $\mathrm{ml}$ of $30 \mathrm{mM}$ 2-Naphthyl acetate mixed with $99 \mathrm{ml}$ of potassium phosphate buffer; $\mathrm{pH}$ 7.2) in separate microtitre plate wells for a and $\beta$-esterases assay respectively and incubated for 15 minutes at room temperature. Fifty $(50) \mu \mathrm{L}$ of fast blue $B$ stain solution was then added to the wells. A separate blank was set up for each of the two esterases containing $20 \mu \mathrm{L}$ of potassium phosphate buffer also mixed with $200 \mu \mathrm{L}$ of the working solutions and $50 \mu \mathrm{L}$ of stain solution. The mixture was read at $570 \mathrm{~nm}$ as an end point assay using a microplate reader (Modulus Microplate Reader; Turner Biosystems Sunnyvale, California, United States). All the assays were performed in triplicates. Absorbance levels for each samples were compared with standard curves of absorbance for known concentrations of anaphthol and $\beta$-naphthol to estimate the activities of a and $\beta$-esterases respectively. The results were reported as micromols $(\mu \mathrm{mol})$ of the product formed/min/mg protein.

\section{Data Analysis}

Significance in mean distribution of the environmental factors across the three study zone was first investigated using mixed effect linear model with study zone as fixed factor and sites as random factor followed by Bonferoni post-hoc test for multiple comparisons. Similarly significance in mean distribution of the detoxification enzymes across the three study zone was investigated using One-way ANOVA followed by Turkey's post-hoc test for multiple mean comparisons. The association or correlation between each environmental factor and the detoxification enzymes activities was analysed using Bivariate Linear Regression with enzyme activity as the fixed factor and the environmental factors as the response variables. To assess the effect of the physicochemical environmental factors on the detoxification enzyme activities, preliminary multiple regression analysis indicated strong colinearity between model covariates. As a result of colinearity, the standard error estimates of the linear regression model get inflated and so the p-values indicating the contribution of different covariates to the model become unreliable. The colinearity problem was addressed by performing a regression in principal components, extracted from the model covariates. Factor analysis was used to extract the principal components (or principal factors) from both the environmental factors and detoxification enzymes variables, followed by a varimax rotation of the principal component axes, to allow a better alignment of the extracted components to the original environmental and enzymatic factors. Then, effect of the physicochemical environmental factors on the detoxification enzymes was assessed by redundancy analysis; involving regression between the extracted principal components of the physico-chemical environmental factors and those of the detoxification enzyme activities that were explaining $99 \%$ of the variability in both cases. All the analyses were carried out with SPSS (SPSS Inc. SAS Institute) version 20. 


\section{RESULTS}

Mean distribution of physicochemical environmental factors across three study zones

Results of the mixed effect linear model showed that the mean distribution of $\mathrm{pH}$, temperature, conductivity DO, BOD, and transparency was not significant (Fig. 1) with P-values $0.163,0.492,0.628,0.234,0.068$ and 0.974 respectively across the three study zones. Likewise, the differences in mean distribution of total dissolved solids, sulphates, phosphates, nitrites, nitrates, carbon content and oil and grease across the three study zones were highly significant $(P=0.000)$ (Fig. 2).

The Bonferoni Post-hoc pairwise comparison tests showed that comparing mean distribution between zone A \& B; A \& C and B \& C for most of the physical environmental factors were not highly significant. For example, for $\mathrm{pH}$, the zone-wise comparisons between zone $A$ against $B, A$ against $C$ and $B$ against $C$ was statistically not significant $(P=0.621,1.000$ and 0.218 , respectively). For dissolved oxygen (DO), there were also no statistically significant differences $(0.327$, 0.620 and 1.000) in mean zone-wise comparisons between zone $A$ against $B, A$ against $C$ and $B$ against $C$, respectively, while for $B O D, A$ against $B, A$ against $\mathrm{C}$ and $\mathrm{B}$ against $\mathrm{C}$ zone-wise comparisons recorded $\mathrm{P}$ values of $1.000,0.152$ and 0.106 respectively. Lastly, same zone-wise comparisons for temperature, conductivity, and transparency were also not statistically significant $(P=1.000)$. However, the zonewise comparisons ( $A$ against $B, A$ against $C$ and $B$ against $C$ ) for TDS and the environmental chemical factors (sulphates, phosphates, nitrites, nitrates, carbon content and oil and grease) were all statistically significant $(P=0.000)$.



A

Study Zones

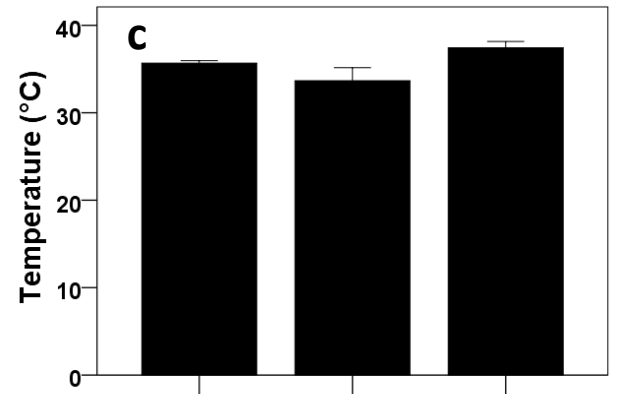

A

B

C

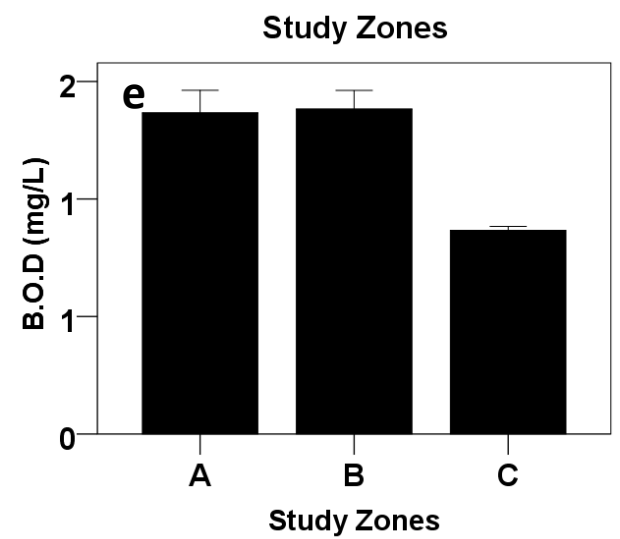

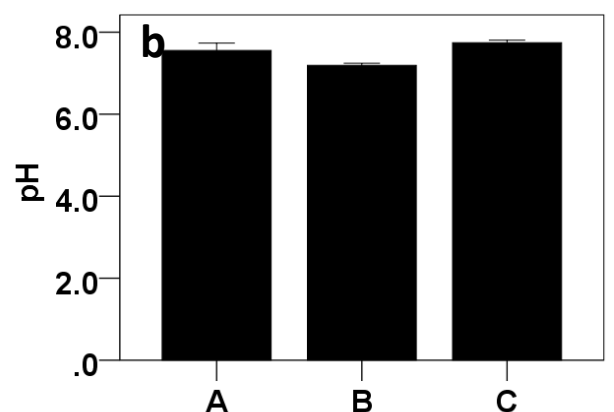

Study Zones

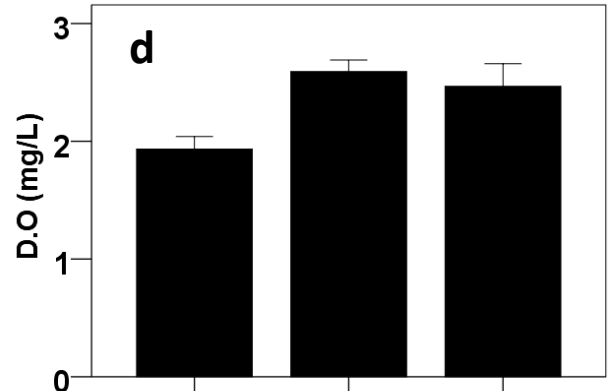

A

B

C

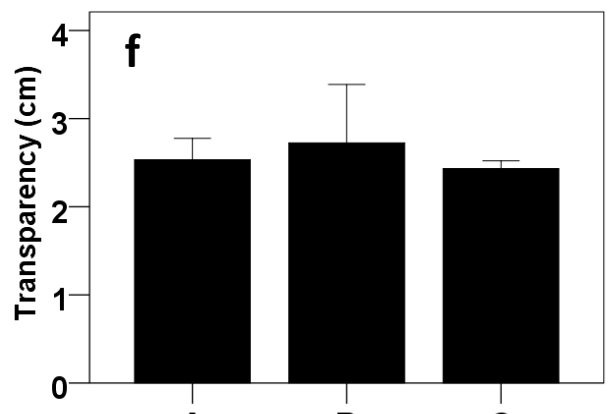

A

B

C

Study Zones

Fig. 1(a-f) Mean distribution of environmental physical factors across three different Anopheles gambiae breeding sites in Northern Nigeria. 

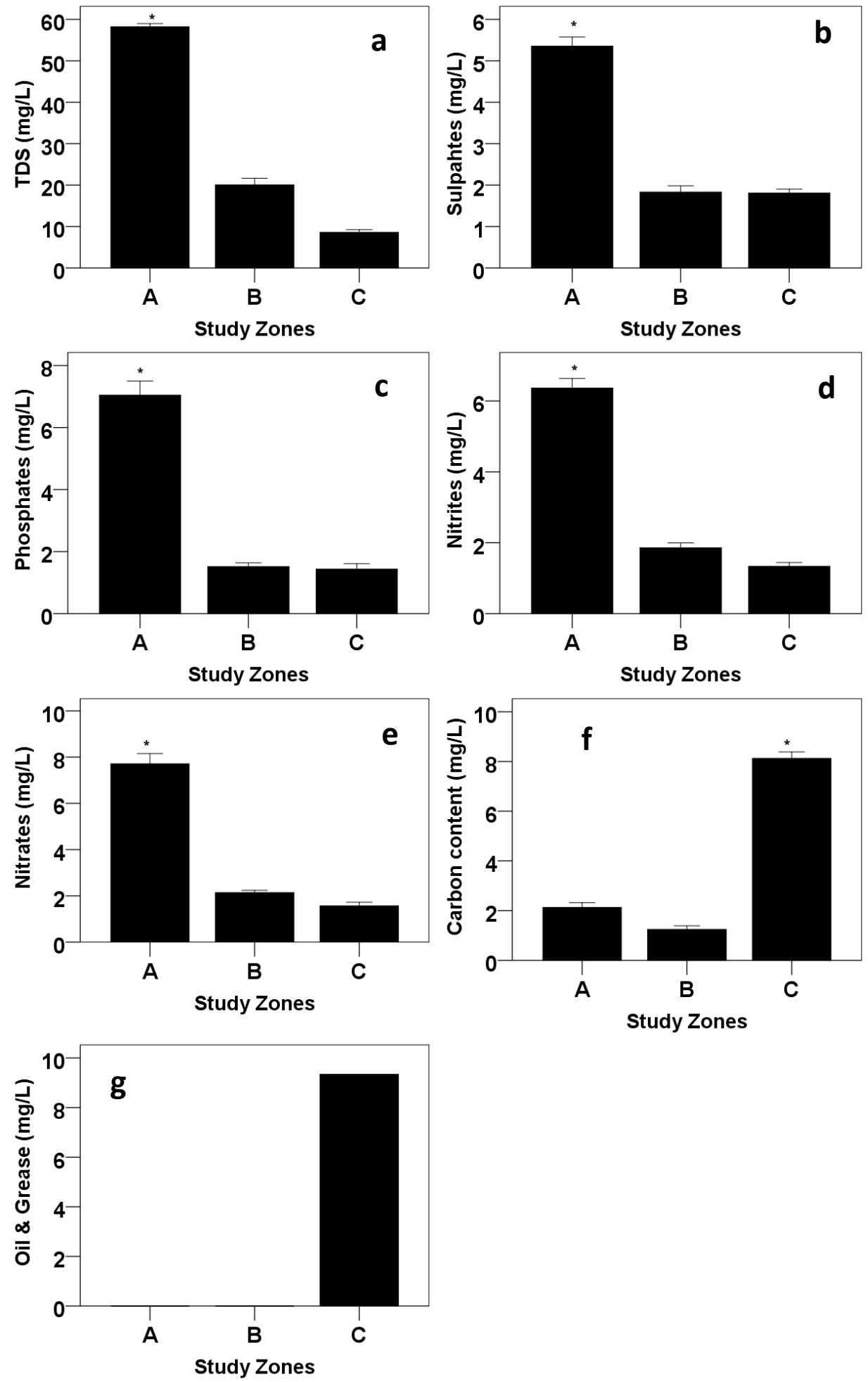

Study Zones

Fig. 2 (a-g) Mean distribution of chemical environmental factors across three different Anopheles gambiae breeding sites in Northern Nigeria.

Mean distribution of the detoxification enzymes across the three study zones

Likewise, the results of the mixed effect linear model showed that the differences in mean distribution of An. gambiae larval P450 activities across the three study zones was statistically significant $(P=0.000)$ with highest mean distribution recorded in study zone $C$ (petrochemical laden). The mean larval P450 activities of zone A and B were 1.7 and 4.3-fold lower than that of zone C. (Fig. 3). Additionally, Bonferoni Post-hoc pair-wise comparism test showed highly significant differences in mean larval $\mathrm{P} 450$ activities between zone $A$ and $B(P=0.008)$ and $B \& C(P=0.000)$. The difference between $A$ and $C$ was moderately significant $(P=0.160)$. Similar observations were recorded for the other two life stages of $A n$. gambiae i.e. pupae and adult. 
In contrast, Anopheles gambiae larvae from study zone A (intensive agricultural sites) recorded the highest mean GST and a \& $\beta$-esterases compared to the other two zones. The differences in mean distribution of these two detoxification enzymes between zone A \& B and A \& C were highly significant
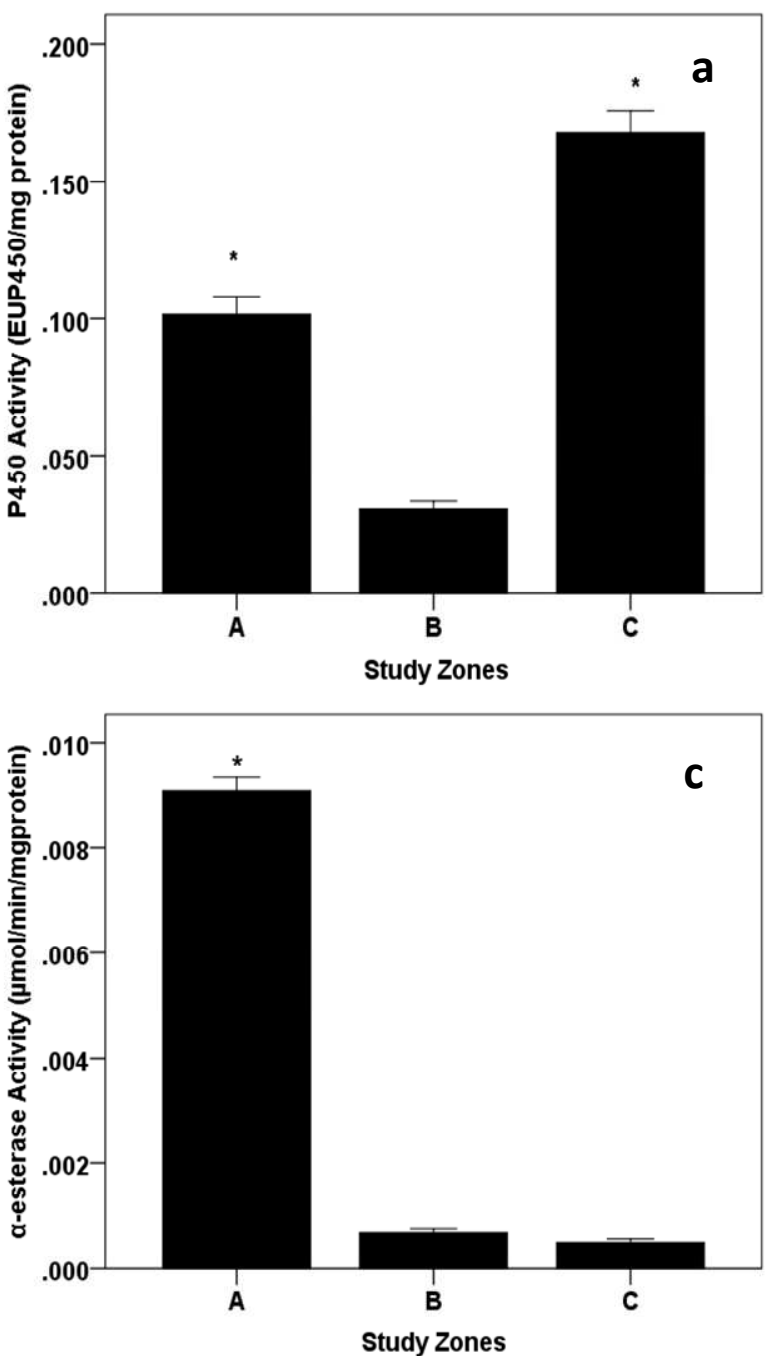

$(P=0.000)$ while differences between zone $B \& C$ was not $(P=1.000)$. (Fig. 3). Like in the case of $P 450$, similar observations were also recorded for the two remaining life stages of $A n$. gambiae (pupae and adult).
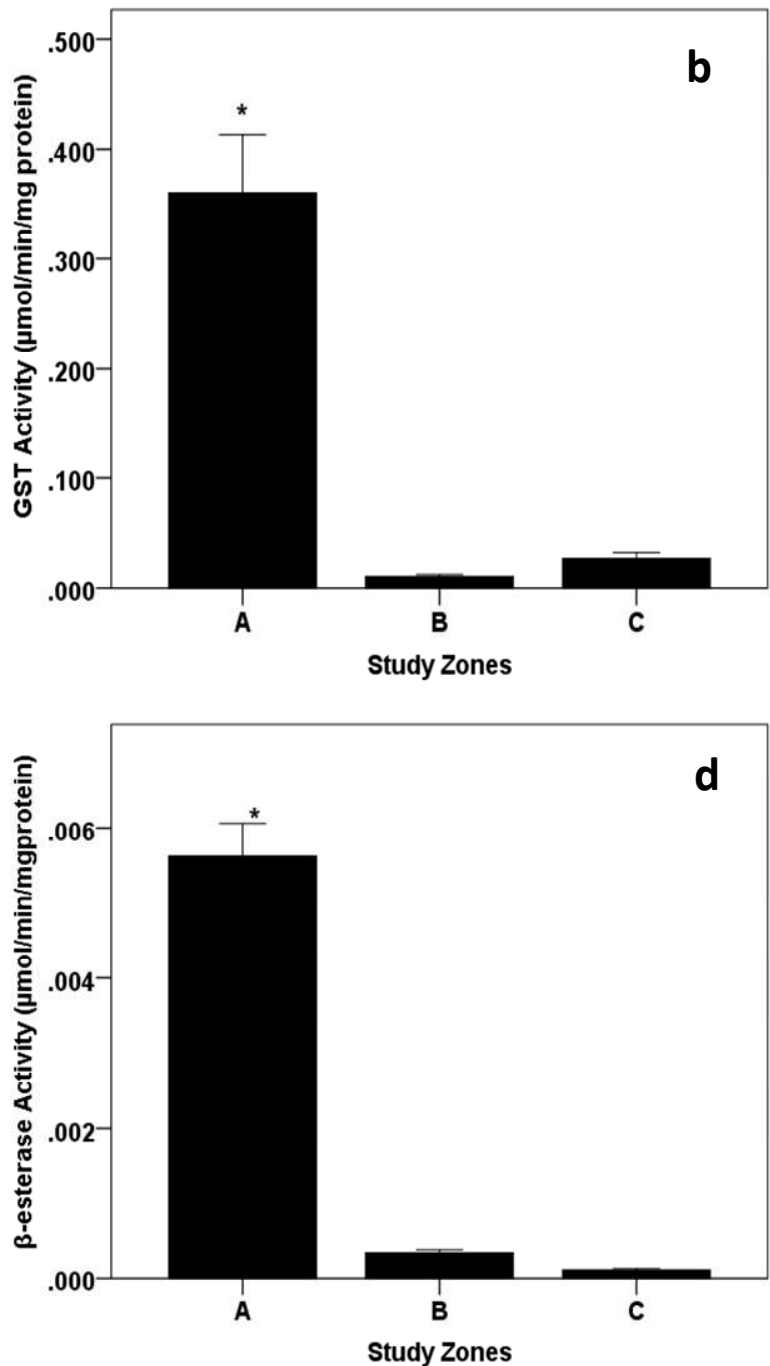

Fig. 3 (a-d) Mean distribution of the four major detoxification enzymes (P450, GST and a \& $\beta$-esterases) at the larval stage of Anopheles gambiae sampled from three different breeding sites in Northern Nigeria.

Association between each physicochemical environmental factors and the detoxification enzymes activities.

Preliminary investigation based on bivariate linear regression analysis between each physico-chemical environmental factors and the detoxification enzymes showed that $\mathrm{pH}$ and temperature were statistically positively associated ( $p=0.000$ and 0.010$)$ respectively, with larval $\mathrm{P} 450$ activities while $\mathrm{BOD}$ showed significant $(p=0.000)$ negative correlation. There were no significant associations $(p=0.655$, 0.806 and 0.416 ) for Conductivity, DO and transparency respectively, and larval P450 activity $(p<0.05)$. Furthermore, the chemical environmental factors; TDS, sulphates, phosphates, nitrites, and nitrates were not significantly associated $(p=0.540$, $0.616,0.465,0.891$ and 0.743 ) respectively, with larval P450 activity while carbon content and oil and grease were significantly positively correlated $(p=0.000)$ with larval $P 450$ activity. This means increase in the levels of carbon content and oil and grease produced increased larval P450 activity. For larval GST and a \& $\beta$-esterase activities, $\mathrm{pH}$, conductivity, and DO were all significantly associated $(p=0.000)$, while temperature, BOD and transparency $(p=0.654,0.713$ and 0.551$)$ respectively, were not. In contrast to P450, the chemical environmental factors; TDS, sulphates, phosphates, nitrites and nitrates showed very strong positive correlation $(p=$ 0.000 ) with larval GST a \& $\beta$-esterase activities while carbon content and oil and grease displayed weak negative associations $(p=0.318$ and 0.063$)$ respectively with GST a \& $\beta$-esterase activities at this life stage. Similar observations were recorded throughout the two remaining life stages of $A n$. gambiae i.e. pupae and adult. 
Bajopas Volume 7 Number 2 December, 2014 Combined effect of the physico-chemical environmental factors on the activities of detoxification enzymes.

In order to deduce a statistical model showing a combination of the physico-chemical environmental factors that produce the most combined significant effect on the detoxification enzymes activities, factor analysis was carried out on both the physico-chemical and detoxification enzymes variables followed by redundancy analysis between the extracted principal components of the detoxification enzymes and those of the physico-chemical environmental variables. Preliminary classical multivariate regression between the environmental variables and the detoxification enzymes failed to produce a reliable model estimates due to strong colinearity among the physico-chemical variables as well as among the detoxification enzymes. Therefore factor analysis was employed to extract components from both the physico-chemical variables and the detoxification enzymes.

The SPSS results of the factor analysis on the physicochemical environmental factors showed that the first eight principal components explained $99 \%$ of the variability in the thirteen environmental variables (Figure 4), and therefore, only these first eight components were retained in the regression analysis. According to the factor loadings, the first component correlated strongly with TDS, sulphates, phosphates, nitrites, and nitrates; component 2 correlated strongly with carbon content and oil and grease, component 3 was explained by conductivity, component 4 by temperature, component 5 correlated with transparency, component 6 was associated with DO, component 7 was explained by $\mathrm{pH}$ while component 8 is correlated with BOD. Thus, the first component represents contamination from pesticides and chemical fertilizer application (fertilizer and pesticides contaminants), component 2 represents contamination from the sale, use, processing, and/or discharge of petrochemical/hydrocarbon products (petrochemical contamination) while components 3-8 represent the physical environmental variables.

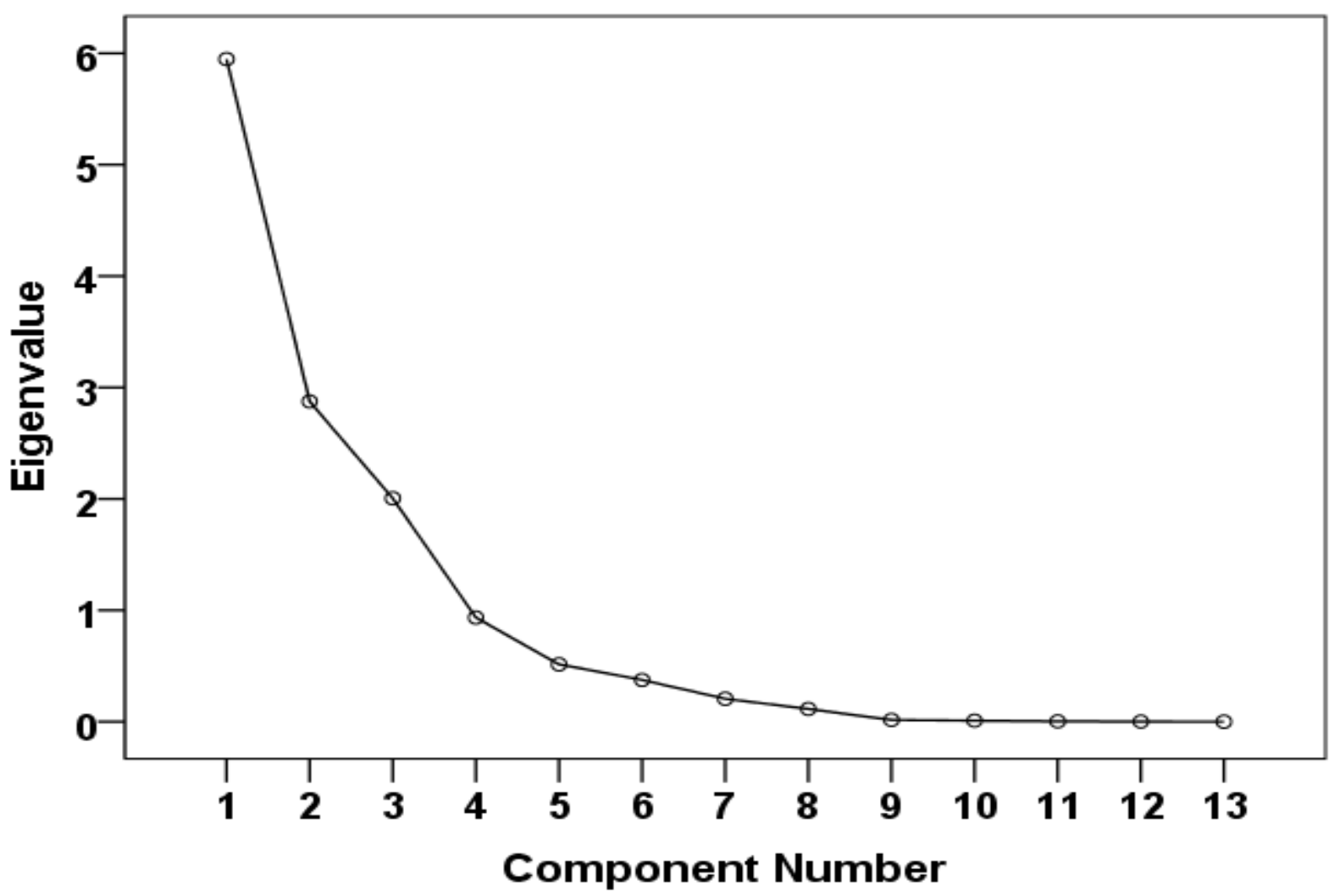

Fig. 4 Scree Plot showing the eigenvalues of the principal components from the factor analysis of the physico-chemical environmental variables.

The result of the factor analysis carried out on the detoxification enzymes produced three extracted principal components (PC) which explained $99 \%$ of the variability in the data. According to the factor loading (Fig. 5) the first principal component (PC 1) correlates strongly with $a$ and $\beta$-esterase activities and some elements of GST, PC 2 correlated with the P450 enzymes activities where as PC 3 was associated with GST alone. Therefore, according to the results of the factor analysis, these three principal components explained more than $99 \%$ of all the variability in the detoxification enzymes irrespective of life stage. As shown in the Scree plot of the extracted principal components (Fig. 5), these three components were distinctly separated from the remaining factors or components that explained little or nothing about the original detoxification enzyme variables. 




Fig. 5 Scree Plot of the extracted components from factor analysis of the detoxification enzyme variables. Components 1-3 explained $99 \%$ of the variability in the data.

The result of redundancy analysis (Table 1 ) between the principal components extracted from the physicochemical environmental variables (i.e. PC1-8; Fig.4)) and GST and $a$ and $\beta$-esterases activities (i.e. PC $1 \& 3$ of the detoxification enzyme variables; Fig. 5) showed that all pesticide and fertilizer contaminants, the petrochemical/hydrocarbon contaminants and only the physical environmental factors; $\mathrm{pH}$, conductivity, transparency, DO and BOD produced the most combined significant effect on the activities of these two enzymes (i.e. GST and $a$ and $\beta$-esterases).

Table 1 Environmental Physicochemical Factors or Components with Combined Effect on GST and a \& $\beta$-esterases across the three Life Stages of An. gambiae.

\section{Hypothesis Test}

\begin{tabular}{cccccc} 
Parameter & Coefficient & Std. Error & Wald Chi-square & df & Sig. \\
\hline Intercept & $8.072 \mathrm{E}-016$ & 0.0194 & 0.000 & 1 & 1.000 \\
PC1 & 0.955 & 0.0198 & 2334.535 & 1 & $<0.001$ \\
PC2 & -0.109 & 0.0198 & 30.603 & 1 & $<0.001$ \\
PC3 & -0.106 & 0.0198 & 28.561 & 1 & $<0.001$ \\
PC4 & -0.010 & 0.0198 & 0.256 & 1 & 0.607 \\
PC5 & -0.070 & 0.0198 & 12.720 & 1 & $<0.001$ \\
PC6 & -0.196 & 0.0198 & 98.394 & 1 & $<0.001$ \\
PC7 & -0.006 & 0.0198 & 0.081 & 1 & 0.776 \\
PC8 & -0.099 & 0.0198 & 25.297 & 1 & $<0.001$ \\
\hline
\end{tabular}

Lastly, the result of the redundancy analysis (Table 2) between the extracted components of the environmental physico-chemical factors and P450 activities (i.e. PC 2 of the detoxification enzyme variables; Fig. 5) showed that, unlike GST and a \& $\beta$ esterases enzymes, all the eight extracted components of the physico-chemical environmental variables (Fig. 4) produced a combined effect on P450 activities. Thus pesticide and fertilizer contaminants, petrochemical contaminants and the physical environmental factors; $\mathrm{pH}$, temperature, conductivity, transparency, DO and BOD all produced a combined effect on the activities of P450 across the three life stages of An. gambiae from Northern Nigeria 
Table 2 Environmental Physicochemical Factors or Components with Combined Effect on P450 across the three Life Stages of An. gambiae.

\begin{tabular}{cccccc}
\hline & & \multicolumn{4}{c}{ Hypothesis Test } \\
Parameter & Coefficient & Std. Error & Wald Chi-square & df & Sig. \\
\hline Intercept & $7.181 \mathrm{E}-016$ & 0.0073 & 0.000 & 1 & 1.000 \\
PC1 & 0.143 & 0.0074 & 373.714 & 1 & $<0.001$ \\
PC2 & 0.940 & 0.0074 & 16178.348 & 1 & $<0.001$ \\
PC3 & 0.038 & 0.0074 & 25.838 & 1 & $<0.001$ \\
PC4 & 0.233 & 0.0074 & 993.202 & 1 & $<0.001$ \\
PC5 & -.0093 & 0.0074 & 159.984 & 1 & $<0.001$ \\
PC6 & 0.138 & 0.0074 & 350.375 & 1 & $<0.001$ \\
PC7 & 0.076 & 0.0074 & 107.203 & 1 & $<0.001$ \\
PC8 & 0.075 & 0.0074 & 103.993 & 1 & $<0.001$ \\
\hline
\end{tabular}

\section{DISCUSSION}

Inductive responses of detoxification systems to xenobiotic overload have been well documented in several organisms including insects. Induction of detoxification enzymes by up-regulation of the genes responsible for their synthesis is one major mechanism employed by organisms to respond to exposure to high levels of environmental chemicals and a number of transcriptions factors regulating this mechanism have been documented in many organisms (Misra et al., 2011). Induction of detoxification enzymes in response to environmental xenobiotics have also been documented in insects. The first documented evidence of enzyme induction in insects was given by Agnosin and Dinamarca, (1963) in which they reported an increased activity of NAD kinase in Triatoma infestans after exposure to DDT. Cytochrome P450s have featured more prominently in many previous studies involving induction of detoxification enzymes in response to environmental xenobiotics in insects, relative to GST and $a$ and $\beta$-esterases (Le Goff et al., 2006) In general, induction of detoxification enzymes in response to several xenobiotic exposures in many insect species have been well documented (David et al., 2013). However, no studies have, to my knowledge, demonstrated the inductive capacity of the environmental chemical species considered in this study on the activities of detoxification enzymes in $A n$. gambiae in Northern Nigeria, despite considerable evidence which indicate that Anopheles mosquitoes thrives in breeding ecologies where they could be exposed to these environmental chemicals.

One of the major mechanisms for the development of insecticide resistance in mosquitoes is detoxification enzymes mechanism. This involved increase in the activities of detoxification enzymes (P450, GST a and $\beta$-esterases) which lead to rapid metabolism of the insecticides before it reaches its sites of action (David et al., 2013; Hemingway et al., 2004). Therefore, exposure of $A n$. gambaie to different environmental chemical compounds presents in its breeding habitats, which could induce increase in activities of these enzymes could potentially produce intrinsic and acquired tolerance to insecticides in mosquitoes emerging from such breeding ecologies, especially if these chemical compounds possess similar structures and activity relationship with the various insecticides used in mosquito control.

A comparative analysis between activities of the detoxification enzymes recorded in this study and those of $A n$. gambiea displaying metabolic resistance to DDT and pyrethroids insecticides (Namountougou et al., 2012; Nwane et al., 2013; Etang et al., 2007) in Nigeria's West African neighbours; Burkina Faso and Cameroun was carried out. In these studies, activities of the three major detoxification enzymes were implicated, among other mechanism, as conferring resistance in strain of $A n$. gambiae in comparism to the Kisumu strain which was used as reference susceptible standards in all of the studies. Comparing the detoxification enzyme activities of the resistant and susceptible reference Kisumu strains reported in these previous studies with the activities recorded in this present study showed that P450 and GST activities favourably compared, and even in many cases, higher than those reported in Burkina Faso and Cameroun resistant strains(Namountougou et al., 2012; Nwane et al., 2013; Etang et al., 2007). However, a-esterase activities recorded in this present study was lower than those from these previous studies. Interestingly, most of the lowest P450 and GST activities recorded in this study were higher than those of the Kisumu susceptible reference standards used and reported in the Burkina Faso and Cameroun studies(Namountougou et al., 2012; Nwane et al., 2013; Etang et al., 2007). While this comparative analysis was not intended to indicate that the $A n$. gambiae samples in this study were also resistant to these insecticides, the result nevertheless serve to establish comparism with strains of An. gambiae confirmed to be displaying metabolic resistance to various insecticides through the activities of these detoxification enzymes. However, the results suggest that the population of mosquitoes in some of these breeding ecologies studied in Northern Nigeria may have developed or are selectively being primed to develop resistance to insecticides. 
This study thus revealed that $A n$. gambiae emerging from breeding sites located in study zone $A$ and $C$ could be selected for potential tolerance to insecticides, especially those having similar structures and activity relationship to the environmental chemical compounds present in high levels in these breeding sites. Studies from previous studies have demonstrated the contribution of prior exposure to various environmental xenobiotics to the development of insecticides resistance by several insect species. Boyer (Boyer et al., 2006) reported that Aedes aegypti larvae exposed to the herbicides atrazine became more tolerant to the organophosphate temephos. Similarly, exposure of Aedes albopictus larvae to benzothiazole and pentachlorophenol increased their tolerance to insecticides such as cabaryl, rotenone, and temephos (Suwanchaichinda and Brattsen, 2001; 2002). In addition, other studies have established a correlation between increase in tolerance to insecticides in many insects and induction of detoxification enzymes as a result of prior exposure to environmental xenobiotics (Feyereisen, 2005; Hemingway et al., 2002; Namountougou et al., 2012). Furthermore, finding from previous study (Poupardin et al., 2008) further highlighted the contribution of prior exposure of mosquitoes to environmental xenobiotics to the development and emergence of insecticides resistance. In this study, Aedes aegypti larvae were exposed to sub-lethal concentrations of three different xenobiotics likely to be found in highly polluted breeding sites. These xenobiotics include the herbicide atrazine, the polycyclic aromatic hydrocarbon fluoranthene and the heavy metal copper. The larvae were then exposed to two chemical insecticides; the organophosphates temephos and the pyrethroids permethrin. Larval tolerance to the insecticides and detoxification enzymes were compared. The results showed a marginal increase in tolerance to the insecticides in the presence of the xenobiotics and the discussion suggests that the phenomenon might even be more pronounced in highly polluted breeding sites or following temporary dramatic pollution events (Poupardin et al., 2008). While many of these previous studies established relationship between exposures to some environmental xenobiotics and incidence of insecticides resistance in various mosquito species, this present study was conducted at the level of pre-insecticide exposure to implicate some broad-base human activities, such as those described in this study, as potentially driving intrinsic and acquired tolerance to insecticides in $A n$. gambiae in Northern Nigeria. Moreover, An. gambiae has not featured prominently in many of these previous studies and none of these studies have to my knowledge been carried out in Northern Nigeria. Thus, this study became necessary in view of the fact that An. gambaie is the major malaria vector in Nigeria (Okwa et al., 2009) and Nigeria accounts for the highest malaria deaths in Sub-Saharan Africa (WHO, 2013). Findings from this study were also consistent with observations from several previous studies which implicated agricultural practices as a selection factor in the development and emergence of insecticides resistance in various insect species from many other parts of the world. For instance, Georghiou (Georghiou, 1982) demonstrated organophosphate resistance in $A n$. albimamus following intensive treatment of cotton pest with pesticides in ElSalvador. The resurgence of malaria in India and Central America was linked to intensive agricultural production employing intensive use of agricultural pesticides (Chapin and Wasserstrom, 1981). Brogdon (Brogdon et al., 1988) demonstrated elevated levels of acetylcholinesterase activity in An. albimamus in intensively managed agricultural areas in Guatemala. Furthermore, a comparative analysis involving two malaria vectors; $A n$. nigerrimus and $A n$. culcifaciens was carried in Sri Lanka. The former breeds in intensive agricultural areas while the latter breeds in non agricultural areas. The results of the analysis showed that An. nigerrimus was resistant to organophosphate and carbamates at both larval and adult stages while $A n$. culcifaciens was not. This established the role of agriculture as source of selection pressure for development of resistance in An. nigerrimus (Hemingway et al., 1986). These and other similar studies have established the impact of agricultural practices in the emergence and development of insecticides resistance. Majority of these studies focused primarily on the role of the use of agricultural pesticides as selection factor in the development of resistance to public health insecticides. But other agrochemicals other than pesticides, such as fertilizer studied here, could also play an important role. In addition, most of these previous studies were conducted at the level of postinsecticides exposure. However, similar studies carried out at the level of pre-insecticides exposure are necessary in order to evaluate the extent and nature of the role of various agricultural practices as selection pressure for the development and emergence of insecticides resistance in public health vectors. Thus, this present study, which to my knowledge is the first of its kind in Northern Nigeria, aim to bridge this gap by assessing the importance of two major agricultural practices; pesticide and fertilizer application, as potential sources of selection pressure for the development and emergence of insecticides resistance in $A n$. gambiae in Northern Nigeria.

The effect of the presence of petrochemical/hydrocarbon products on the growth, survival and biochemical behaviour of An. gambiae has not, to my knowledge, been largely investigated, despite an age long tradition of applying these products to mosquito breeding waters to control mosquito larvae (Burton, 1967; Rozendahl, 1997). Findings from previous studies (Ekom, 2006; Obire and Anyawu, 2009; Adekunle et al., 2010; PatrickIwuanyanwu et al., 2011) have however demonstrated several effects of petrochemical products on many other aquatic organisms in Nigeria. The induction of cytochrome P450 systems in response to exposure of insects to petrochemical products has not been largely investigated. However, since this enzyme system together with the other detoxification machinery are also conserved in insects (Strode et al., 2008), inferences from findings in other organisms can be used to explain the observations made in this present study. 


\section{CONCLUSION}

This study has demonstrated the significance of the physico-chemical environmental factors present in mosquito breeding sites, not only on the growth, development and survival of An. gambiae, but also on their detoxification enzymes machinery. Significant associations were established between several physico-chemical environmental factors and activities of three major detoxification enzymes (P450s, GSTs

\section{REFERENCES}

Adekunle, I. M., Ajijo, M. R., Adeofun, C. O., and Omoniyi, I. T. (2010). Response of four phytoplankton species found in some sectors of Nigerian coastal wates to crude oil in controlled ecosysytem. Int. Journ. Environ. Res, 4 (1): 65-74, Winter 2010 ISSN: 17356865.

Agnosin, M., and Dinamarca, M L (1963). The effect of DDT on the level of di-and triphosphopyridine nucleotides in Triatoma infestans. Exp. Parasitol. 13: 199-203

Boyer, S., Serandoor, J., Lempeirerre, G., Raveton, M., and Ravanel, P. (2006). Do Herbicide Treatments reduce the sensitivity of mosquito larva to insecticides? Chemosphere 65 (2006):721-724.

Brogdon, W. G., Beach, R. F., Stewart, J. M., and Castanza, L. (1988). Microplate Assay Analysis of the Distribution of organophosphate and Carbamate Resistance in Guatemalan Anopheles Albipictus. Bulletin of the World Health Organisation 66: 339346

Budiansky, S. (2002). Creatures of our own making. Science 298:80-86

Burton, G J (1967). Observations on the habitats and control of Culex pipens fatigans in Guyana. Bulletin of the World Health Organisation 1967, 37:317-322

Chapin, G., Wasserstrom, R. (1981). Agricultural Production and Malaria Resurgence

David, J. P., Ismail, A. M., Chander-Proust, A., and Paine, M. J (2013). Role of cytochrome P450s in insecticide resistance: impact on the control of mosquito-borne diseases and use of insecticides on earth. Phil. Trans. R. Soc. B. 368:20120429.

Ekom, R. A. (2006). Effect of waste engine oil on phytoplankton of the Calabar River Estuary, Nigeria. Global Journal of Environmental Sciences, 292, 112-117.

Etang, J., Manga, L., Toto, J-C., Guillet, P., Fondjo, E., and Chandre, F (2007). Spectrum of metabolic based resistance to DDT and pyrethroids in Anopheles gambiae s.l. populations from Cameroun. Vector Ecology 3(1) 123-133.

Feyereisen, R. (2005). Insect's Cytchrome p450. In: L. I. Gilbert, K. Latrou and S. Gill (eds.) Comprehensive Molecular Insect Science. Elsevier 1-77.

Georghiou, G. P. (1982). The Surveillance of Pest Resistance to Insecticides in Agriculture. Proceed. Int. Work: Resistance to and Carboxylesterases) in An. gambiae. The levels and characteristics of these environmental factors were related to the various human activities taking place around the mosquito breeding sites. Analyses of the significance of these findings and observations and inferences from previous studies have demonstrated the impact this study could produce on the contemporary integrated vector control approach to malaria management.

Insecticides Used in Public Health and Agriculture. 22-26 Feb. 1982. Nat. Sci. Council, Sri Lanka 46-62

Hemingway, J., Field, L., and Vontas, J. (2002). An overview of insecticides resistance, Science 298:96-97

Hemingway, J., Hawkes, N. J., McCaroll, L., and Ranson, H. (2004). The molecular basis of insecticides resistance in mosquitoes. Insect. Biochem. Mol. Biol. 34:653-665

Hemingway, J., Jayawardena, K., and Herath, P. R. (1986). Pesticides Resistance Mechanisms Produced by Field Selection Pressure on Anopheles nigerrimus and $A$. culicifacies in Sri Lanka. Bulletin of the World Health Organisation 64:753-758.

In Central America and India. Nature 293:181-185.

John, I. (2007). Africans: the history of a continent. Cambridge University Press. ISBN 0.52186438-0 p75.

Le Goff, G., Hilliou, F., Segfried, B D., Boundy, S., Wajnberg, E., Sofer, L., Audant, P., FfrenchConstant, R H., Feyereisen, R (2006). Xenobiotic response in Drosophila melanogaster: sex dependence of p450 and GST gene induction. Insect. Biochem. Mol. Bio/36:674-682

Maiti, S K (2004). Handbook of methods in environmental studies: water and waste water analysis. ABD Publishers, India Pp31173

Misra, J R., Horner, M A., Lam, G., and Hummel, C S (2011). Transcriptional regulation of xenobiotic detoxification in Drosophila. Genes \& Development 25:1796-1806 Pub. by Cold Spring Harbour Press ISSN 0890-9369/11

Namountougou M, Simard F, Baldet T, Diabate' A, Oue'draogo JB, et al. (2012) Multiple Insecticide Resistance in Anopheles gambiae s.l. Populations from Burkina Faso, West Africa. PLoS ONE 7(11): e48412. doi:10.1371/journal.pone.0048412

NIMET, (2012). Nigerian Meteorological Agency, Abuja-Nigeria. www.nimetng.org

Nwane, P., Etang, J., Chouabou, M., Toto, J-C., Koffi, A., Minpfoundi, R., and Simard, F (2013). Multiple insecticides resistance mechanisms in $A n$. gambiae s.l. population from Cameroun, West-Central Africa. Parasites \& Vectors 6:41.

Obire O and Anyawu, E.C. (2009). Impact of various concentrations of crude oil on fungal populations of soil, Int. J. Environ. Sci. Tech., 6(2), 211-218. 
Bajopas Volume 7 Number 2 December, 2014

Okwa, O. O., Akinmolayan, F. I., Carter, v., Hurd, H (2009). Transmission dynamics of malaria in four selected ecological zones of Nigeria in the rainy season. Ann. Afr. Med. 8(1):1-9

Patrick-Iwuanyanwu, K.C., C.C. Onyemaenu, M.O. Wegwu and E.O. Ayalogu, (2011). Hepatotoxic and nephrotoxic effects of kerosene and petrol-contaminated diets in wistar albino rats. Res. J. Environ. Toxicol. 5: 49-57.

Perry, T., Batterham, P., and Daborn, P J. (2011). The biology of insecticidal activity and resistance. Insect Biochem. Mol. Biol. 41: 411-422

Poupardin, R., Reynad, S., Strode, C., Ranson, H., Vontas, J., and Jean-Philippe, D. (2008). Cross-induction of detoxification genes by environmental xenobiotics and insecticides in the mosquito; Aedes aegypti. Impact on larval tolerance to chemical insecticides. Insects. Biochem. Mol. Biol. 36 (2008):540551

Riaz, M. A., Poupardin, R., Reynaud, S., Strode, C., Ranson, H., David, J P. (2009). Impact of glyphosate and benzo[a]pyrene on the tolerance of mosquito larvae to chemical insecticides: Role of detoxification genes in response to xenobiotics. Aquatic Toxicology 93: $61-69$

Rozendaal J. A (1997) Vector control: methods for use by individuals and communities. Alden Press7500 England. ISBN 9241544945 Pp129-130

SEEDS, (2009). State Economic Empowerment and Development Strategy: Jigawa Statec comprehensive development framework Jigawa State Nigeria. Pp2-12

Service M. W (1993). Mosquito ecology: field sampling methods. Elsevier Applied Science, London. Second Edition 1993. pp8-21

Strode, C., Steen, K., Ortelli, F., and Ranson, H (2006). Differential expression of detoxification genes in the different life stages of the malaria vector Anopheles gambiae. Insect Molecular Biology 15(4): 523-530

Strode, C., Wondji, C. S., David, J. P., Hawkes, N. J., Lumjuan, N., Nelson, D. R., Drane, D. R., Karunaratne, S. H., Hemingway, J., Black, W C 4th., Ranson, H (2008). Genome analysis of detoxification genes in the mosquito Aedes aegypti. Insect Biochem. Mol. Biol. 38(1):113-23.

Suwanchaichinda, C. and Brattsen, L. B. (2001). Effects of exposure to pesticides on carbaryl Toxicity and cytochrome P450 activities in Aedes albopictus larvae (Dipteria Culicidae). Pestic. Biochem. Physiol. 70 (2001):63-73.
Suwanchaichinda, C. and Brattsen, L. B. (2002). Induction of microsomal cytchrome P450s by tire-leachate compounds, habitat components of Aedes albopictus mosquito larvae. Arch. Insect. Biochem. Physiol. 49 (2002):71-79.

Vontas, J., Blass, C., Koutsos, A C., David, J P., Kafatos, F C., Louis, C., Hemingway, J., Christophidies, G K., Ranson, H. (2005). Gene expression in insecticides resistant and susceptible strains constitutively or after insecticides resistance. Insect. Mol. Biol 14: 509-521

WHO (1998). Techniques to detect insecticide resistance mechanisms (field and laboratory manual). WHO/CDS/CPC/MAL/98.6 Geneva

WHO (2013). World Health Organisation Malaria Fact Sheets N94 Jan. 2013. www.who.int/mediacentre/factsheet.fs094/e $\underline{\mathrm{n}}$

Xu, C., Li, C. Y., and Kong, A. N (2005). Induction of phase I, II and III drug metabolism/transport by xenobiotics. Arch. Pharm. Res. 28(3):24968

Yu, S. J. (2005). Detoxification mechanisms in insects. Encyclopedia of Entomology 4:687-699 